\title{
Nasal Secretion Cytology of Children Attending a Primary School in Enugu Metropolis - A Preliminary Evaluation using the Blow-out Technique
}

\author{
Nkiruka C. Azubuike and Obioma C. Ejiogu
}

\section{ABSTRACT}

Nasal smear is a valid method used to distinguish inflammatory and noninflammatory conditions. The present study was conducted to evaluate the cytological picture and neutrophilic infiltration of nasal secretions of children from a primary school within Enugu metropolis in Enugu State, Nigeria. The study included 100 apparently normal pupils, 20 each from grade levels 1 to 5 . The blow-out technique was used to obtain samples from the nasal cavity for smear preparation on slides. May-GrunwaldGiemsa was used to stain the smears for light microscopical examination. Smears were assessed for the presence of infiltrating inflammatory cells and a semi-quantitative grading of neutrophilic infiltration was conducted on each sample to indicate either absent, few, moderate or many. Mean age of participants is $6.25 \pm 0.44$ years (range: 6-11 years). Results revealed that age and grade level of study had a strong association with the grade score of neutrophilic infiltration $(p<0.05)$. Grade level 1 pupils, the youngest group (mean age: $6.25 \pm 0.44$ years), had the highest abnormal cytological picture and neutrophilic infiltration while those in grade levels 3 to 5 who were older, were lower. There was no association between gender and neutrophilic infiltration. It can be concluded that significantly increased neutrophilic infiltration are obtained in the nasal secretions of younger schoolchildren below the age of 9 than the older pupils. This study also indicates that the blow-out method is a useful technique for obtaining nasal secretions for the assessment of infiltrating cells.

Keywords: Nasal secretions; Cytology; Neutrophils; Children; Primary School.

\section{INTRODUCTION}

The nose is part of the respiratory system, and it is easily accessible for evaluation, either morphological or pathophysiological. Morphological changes in the nasal mucosa are of interest not only in the routine clinical examination of lesions and infections but also for researchoriented studies [1]. Immunological reactions which occur in the airway mucosa may be as a result of naturally occurring disease or by induction [2], [3].

The nasal and paranasal sinus mucosa are directly exposed to air born allergens, thus making them the most common shock organs of nasal allergy and inflammatory diseases. The evaluation of the cells located within the nasal septum is achieved by obtaining a nasal smear.

Since nasal smear has been employed for several years in the detection of cellular changes of the epithelium caused by either physical or chemical inflammation [4], it has become a valuable diagnostic tool in both clinical and research studies, thus enhancing the study of nasal disorders such as rhinitis, sinusitis, and nasal polyps [5]. The diagnostic
Submitted : June 11, 2021

Published : July 05, 2021

ISSN: $2593-8339$

DOI: $10.24018 /$ ejmed.2021.3.4.930

\section{N. C. Azubuike*}

Histopathology and Cytopathology

Unit, Department of Medical Laboratory Sciences, Faculty of Health Sciences and Technology, University of Nigeria, Enugu Campus, Nigeria. (e-mail: nkiruka.azubike@ unn.edu.ng) O. C. Ejiogu

Department of Medical Laboratory Sciences, Faculty of Health Sciences and Technology, University of Nigeria, Enugu Campus, Nigeria.

General Hospital Ashaka, Ashaka Ndokwa East Local Government Area, Delta State.

(e-mail: obiomaejiogu@ gmail.com)

*Corresponding Author technique is simple, painless, non-invasive and less cost effectiveness, thus enabling a repeat of the examination in follow-up of patients and therapy monitoring. The major limitation to this technique is its standardization to be used as a reproducible methodology [6].

The mucosal surfaces of the respiratory tract are lined by a secretory layer which contains proteins responsible for bacterial growth inhibition and prevention of microorganisms' invasion. The composition of nasal secretions varies considerably in pathological conditions such as allergic diseases and infection [7]. Collection of nasal secretions for smear evaluation can be achieved by blow-out technique, insertion of a saline nasal tampon, aspiration after stimulation with cellulose sponge, swabbing with a cotton applicator or by collection in a specimen bottle at periods of acute exacerbation [8], [9]. The diagnostic procedure for nasal smear, though being simple with proven usefulness and requiring only a less sophisticated instrument (Light microscope), has remained an underused technique [10].

In schoolchildren, infections and/or inflammatory disorders of the nasal mucosa often have a multi- 
dimensional impact on their health-related quality of life leading to discomfort, impaired sleep, irritability and ultimately school absenteeism if not properly managed [11], [12], thus, there is a need for periodic biomonitoring. The present study was therefore aimed to evaluate the cytological picture of nasal secretions of apparently normal children in a primary school in Enugu Metropolis. Emphasis was given to semi-quantitative grading of neutrophilic infiltration and the relationship between with other factors such as age, gender and grade level of study was also established.

\section{METHODS}

\section{A. Study Location}

The study was carried out in WTC (Women Training College) Primary School Ogui, New Layout, Enugu, Enugu State, Nigeria. The School is made up of Five Primary School Blocks with 5 Headmistresses (one for each School block).

\section{B. Ethical Consideration/Consent}

Ethical clearance for this study was obtained from the Health Research and Ethics Committee of the University of Nigeria Teaching Hospital, Ituku-Ozalla [NHREC/05/01/2008B-FWA00002458-1RB00002323].

Before sample collection, administrative permission from the Primary School was sought with an introductory letter from the Department of Medical Laboratory Sciences, University of Nigeria, Enugu Campus. Copies of this administrative permit and a self-constructed letter bearing the purpose of the study was outlined and submitted to each of the various Headmistresses of the 5 Primary School Blocks, after which an approval was granted. Written informed consent was also obtained from the pupils' guardians/parents for their participation in the study before the collection of samples.

\section{Study Group/Sampling Technique}

The total population of WTC Primary School is 1045 pupils. Out of this population, only 100 pupils were recruited for this study. Pupils aged 6 to 11 years, who can produce the samples and who were not on antibiotics or have had any previous surgical operation in the nasal regions, were selected. Multi-stage cluster sampling technique was used for this study. Twenty (20) pupils (comprising of 10 girls and 10 boys) were randomly selected from each School block to make a total of 100 pupils.

\section{Sample Collection}

One hundred (100) nasal secretions were collected from the participants using the blowing technique as previously described [13]. The specimen is blown out from the nasal region unto a piece of wax paper or plastic film paper.

\section{E. Sample Processing}

Each specimen produced on a wax paper was collected with the aid of an Applicator Stick and smeared on a welllabelled frosted glass slide. Special care was taken to avoid traumatizing the cells. For the fixation of the specimen on the slide, ninety-five percent $(95 \%)$ methanol was used. This was allowed to air dry for 2-8 minutes before staining with May-Grunwald- Giemsa (10\%) stain for 10 minutes. The stain was thereafter poured off and the slide rinsed with distilled water for 20 seconds for staining enhancement. The slide was blotted with Whatman filter paper to wipe off excess stain. After air drying, the slide was viewed microscopically with $\mathrm{x} 40$ objective lens and later with $\mathrm{x} 100$ (oil immersion). Presence of cellular infiltrates and bacteria were noted for each slide. Neutrophil infiltration was semiquantitatively graded as previously described [6], but with slight modification. At least 25 fields (High power) were viewed, and the absence of cells was termed 'none' and graded as 0 , 'few'- for few scattered cells (small clumps) as $1+$, 'moderate'- for moderate number of cells with few large clumps as $2+$, and 'many' for large clumps which may cover the entire field as $3+$.

\section{F. Data Analysis}

Data obtained in this study were analyzed using Statistical Package for Social Sciences (SPSS) version 20 (Inc., Chicago, IL, USA). The mean age of participants was expressed as Mean \pm standard deviation. Descriptive statistics were employed to determined categorical variables like percentages, and the results were presented in frequency tables. Overall effects of age, gender, and grade level of education on the cytological picture and microscopical grading of neutrophil infiltration were determined using Chi square test at $95 \%$ confidence limit and significance of $5 \%$ probability level $(\mathrm{p}<0.05)$

\section{RESUlTS}

A total of 100 samples from the school children were used in the present study comprising of 50 females and 50 males. The mean age of all the participants was 8.5 years (standard deviation [SD]: 1.66; range: 6-11 years; median age: 9 years). The mean ages of pupils are $6.25 \pm 0.44$ years (Grade 1), $8.00 \pm 0.00$ years (Grade 2), $9.0 \pm 0.00$ years (Grade 3 ), $10.00 \pm 0.00$ years (Grade 4 ) and $11.00 \pm 0.00$ years (Grade $5)$.

Table I shows the cytological picture status of the nasal secretion obtained from the participants according to age group, gender, and grade level of education. The cytological picture was indicated as either normal or abnormal and a higher frequency $(52 \%)$ of normal cytological picture was observed whereas 48 samples showed abnormal cytological picture.

According to age, children greater than 8 years of age had a higher frequency of normal cytological picture unlike those of younger age. No difference was observed between females and males of the population studied. Pupils in grade levels 3 and 4 had high frequencies of normal cytological picture whereas children in grade 1 had the lowest.

Table II shows the microscopy grading (with high power field) of the neutrophilic infiltration in the nasal secretions [NS] obtained from the children using the blow-out technique. Children in age group 6-8 years had more cases with moderate (20\%) and many (numerous) (10\%) presence of neutrophils in the NS while those in age group 9-11 years had fewer cases of $16 \%$ and $2 \%$ respectively. There was a significant association between age and neutrophilic infiltration in NS of the children $(p<0.01)$. Conversely, no 
association was observed between gender of children and neutrophilic infiltration. Children in grade 3 had highest frequency $(14 \%)$ of samples with absence of neutrophils followed by grade 4 and $5(7 \%)$ while those in grades 1 and 2 had the least of 3 cases each. Grades 4 and 5 pupils had no sample with numerous neutrophilic infiltrations while grade 1 pupils had the highest frequency accounting for 8 cases with numerous presences of neutrophils. Chi square also revealed an association between the grade level of pupils and presence of neutrophils in NS $(\mathrm{p}<0.01)$.

TABLE I: CYTOLOGICAL PICTURE OF THE NASAL SECRETIONS FROM THE

\begin{tabular}{cccc}
\multicolumn{3}{c}{ SCHOOL CHILDREN OBTAINED BY LOW-OUT TECHNIQUE } \\
\cline { 1 - 2 } Characteristics & \multicolumn{2}{c}{ Cytological Picture } \\
\cline { 2 - 3 } & Normal & Abnormal & \\
\hline Age group & & & \\
6-8 years & $10(25 \%)$ & $30(75 \%)$ & $40(100 \%)$ \\
9-11 years & $42(70 \%)$ & $18(30 \%)$ & $60(100 \%)$ \\
\hline \multicolumn{4}{c}{$X^{2}=19.471 ; \mathrm{p}=0.000$} \\
\hline Gender \\
Females & $26(52 \%)$ & $24(48 \%)$ & $50(100 \%)$ \\
Males & $26(52 \%)$ & $24(48 \%)$ & $50(100 \%)$ \\
\hline \multicolumn{4}{c}{$X^{2}=0.000 ; \mathrm{p}=1.000$} \\
\hline Grade & $3(15 \%)$ & $17(85 \%)$ & $20(100 \%)$ \\
Level 1 & $7(35 \%)$ & $13(65 \%)$ & $20(100 \%)$ \\
Level 2 & $15(75 \%)$ & $5(25 \%)$ & $20(100 \%)$ \\
Level 3 & $16(80 \%)$ & $4(20 \%)$ & $20(100 \%)$ \\
Level 4 & $11(55 \%)$ & $9(45 \%)$ & $20(100 \%)$ \\
Level 5 & $X^{2}=23.878 ; \mathrm{p}=0.000$ \\
\hline \multicolumn{5}{c}{$52(52 \%)$} & $48(48 \%)$ \\
\hline TOTAL &
\end{tabular}

TABLE II: MICROSCOPICAL GRADING OF NEUTROPHILIC INFILTRATION IN

\begin{tabular}{|c|c|c|c|c|}
\hline \multicolumn{5}{|c|}{ NASAL SECRETIONS } \\
\hline \multirow{2}{*}{ Characteristics } & \multicolumn{4}{|c|}{ Neutrophilic Infiltration } \\
\hline & None & Few & Moderate & Many \\
\hline \multicolumn{5}{|l|}{ Age group } \\
\hline $6-8$ years & $6(15 \%)$ & $4(10 \%)$ & $20(50 \%)$ & $10(25 \%)$ \\
\hline $9-11$ years & $33(55 \%)$ & $9(15 \%)$ & $16(27 \%)$ & $2(3 \%)$ \\
\hline \multicolumn{5}{|c|}{$X^{2}=23.326 ; \mathrm{p}=0.000$} \\
\hline \multicolumn{5}{|l|}{ Gender } \\
\hline Females & $19(38 \%)$ & $7(14 \%)$ & $19(38 \%)$ & $5(10 \%)$ \\
\hline Males & $20(40 \%)$ & $6(12 \%)$ & $17(34 \%)$ & $7(14 \%)$ \\
\hline \multicolumn{5}{|c|}{$X^{2}=0.547 ; \mathrm{p}=0.908$} \\
\hline \multicolumn{5}{|l|}{ Grade } \\
\hline Level 1 & $3(15 \%)$ & $0(0 \%)$ & $9(45 \%)$ & $8(40 \%)$ \\
\hline Level 2 & $3(15 \%)$ & $4(20 \%)$ & $11(55 \%)$ & $2(10 \%)$ \\
\hline Level 3 & $14(70 \%)$ & $1(5 \%)$ & $3(15 \%)$ & $2(10 \%)$ \\
\hline Level 4 & $12(60 \%)$ & $4(20 \%)$ & $4(20 \%)$ & $0(0 \%)$ \\
\hline Level 5 & $7(35 \%)$ & $4(20 \%)$ & $9(45 \%)$ & $0(0 \%)$ \\
\hline \multicolumn{5}{|c|}{$X^{2}=43.803 ; \mathrm{p}=0.000$} \\
\hline TOTAL & $39(39 \%)$ & $13(13 \%)$ & $36(36 \%)$ & $12(12 \%)$ \\
\hline
\end{tabular}

The photomicrographs of selected specimens from the children in all grade levels were captured and are shown as below (Plates 1 to 5). Presence of bacteria, lymphocytes and neutrophils are observed in the specimens.
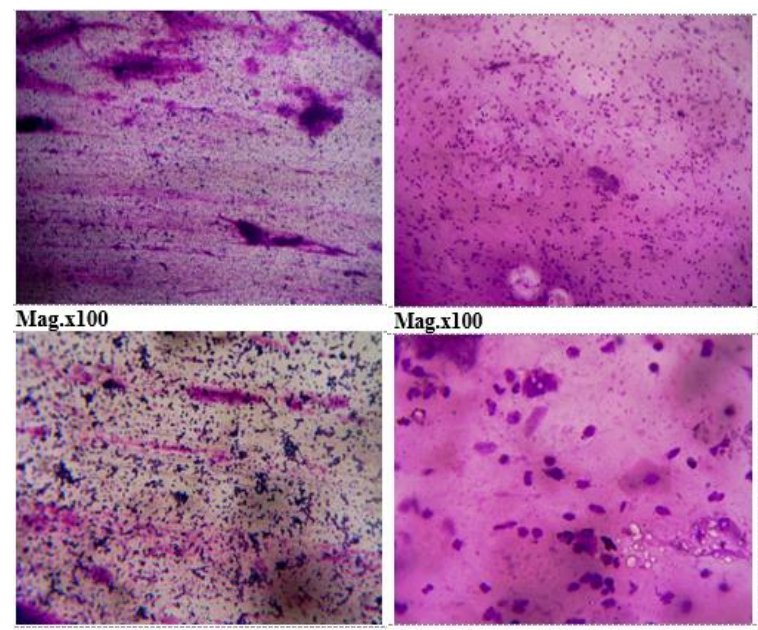

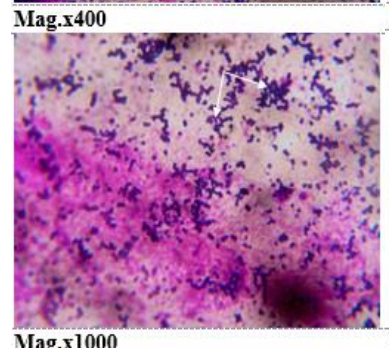

SPECIMEN 4
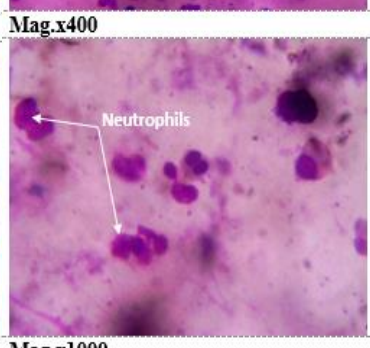

Mag.xl000
Plate 1. Light photomicrographs of nasal mucosal specimen from Grade 1 pupils showing presence of bacteria (arrows) [Specimen 4] and mild neutrophilic infiltration [Specimen 10].
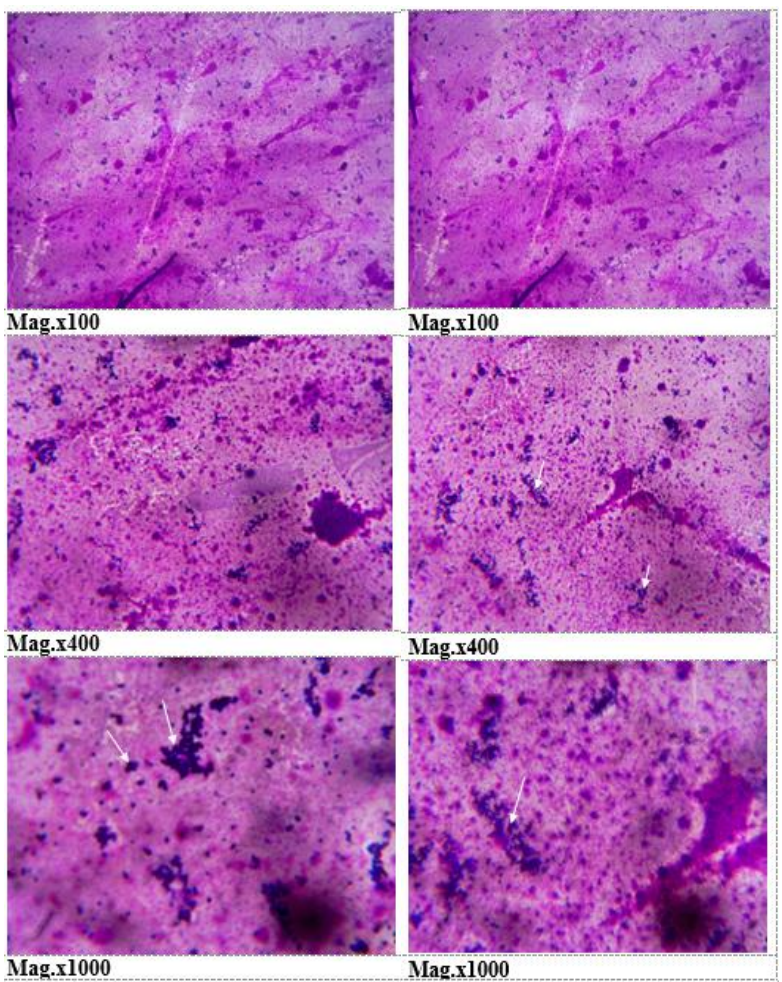

SPECIMEN 70

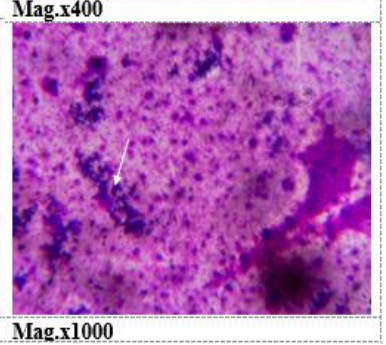

SPECIMEN 90

Plate 2. Light photomicrograph of nasal mucosal specimens from grade 4 and 5 pupils (Specimens 70 and 90 respectively) showing presence of bacteria (arrows) 

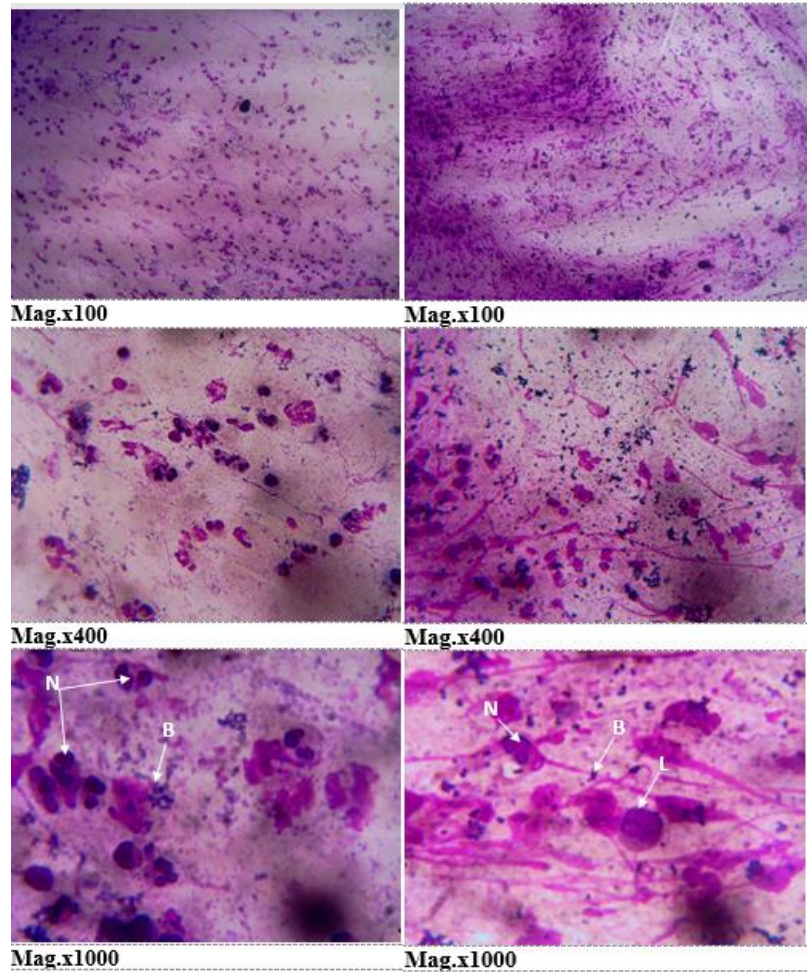

SPECIMEN 40
Mag.x100
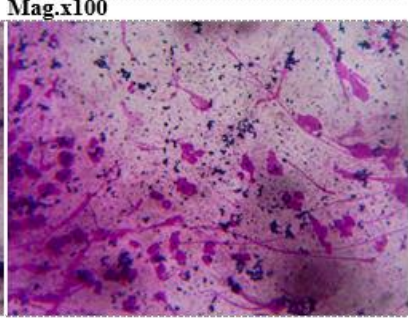

Mag. $\mathbf{4 0 0}$

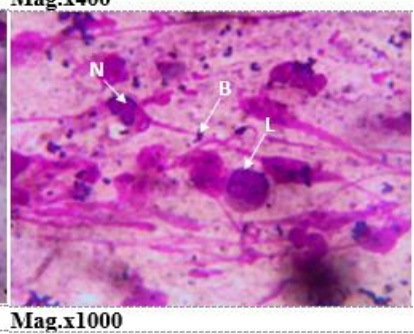

SPECIMEN 100

Plate 3. Light photomicrographs of nasal mucosal specimens from Grade 2 and 5 pupils (Specimens 40 and 100 respectively) showing a mixed population of bacteria (B), moderate neutrophilic infiltration $(\mathrm{N})$ and a few lymphocytes (L).
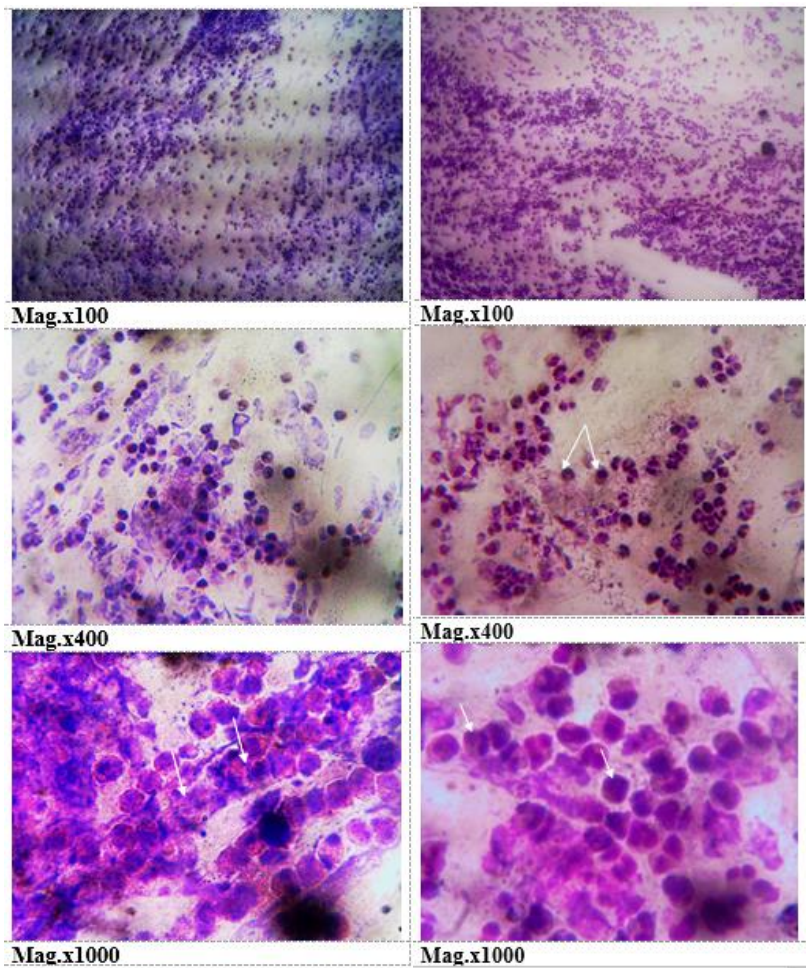

Mag.x100

SPECIMEN 15

SPECIMEN 20

Plate 4. Light photomicrograph of nasal mucosal specimens from Grade 1 pupils showing marked neutrophilic infiltration (arrows).
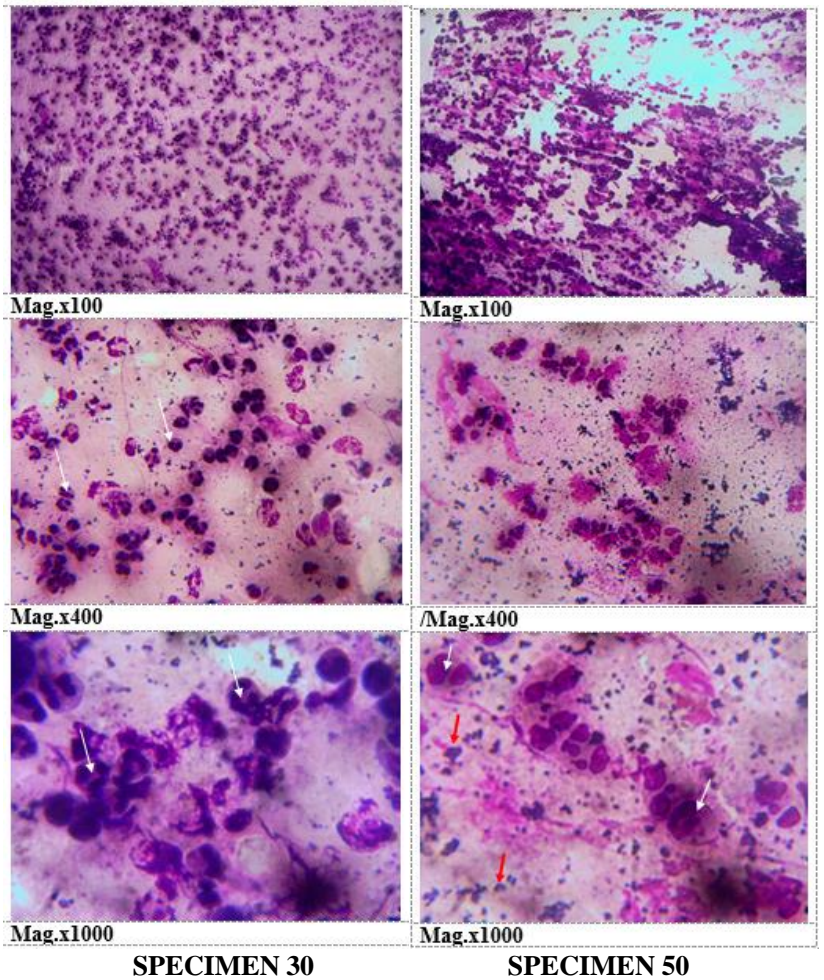

SPECIMEN 50

Plate 5. Light photomicrograph of nasal mucosal specimens from Grade 2 and 3 pupils (Specimens 30 and 50 respectively) showing a mixed population of bacteria (red arrows) and marked neutrophilic infiltration (white arrows).

\section{DISCUSSION}

Nasal smear is a simple paraclinical investigation and it depends on obtaining adequate specimens, appropriately preparing, and staining of smears with May-GrunwaldGiemsa stain. This stain is conventionally used and has been found to be effective for the identification of polymorphonuclear cells. More so, this staining technique is also useful in the diagnosis of inflammatory and noninflammatory disorders, allergic and non-allerjgic infections, viral and bacterial infections in tropical environments which is mostly confronted with quite some unfavourable factors such as pollution, allergy, and social inequalities in health [14]-[16]. In the present study, clear cytological picture of the nasal smear (normal or abnormal) obtained from school children were achieved using MGG stain, and the effect of gender, age and level of study on the cytological picture and neutrophilic infiltration were established.

The sample collection employed in our study for the cytological evaluation of nasal smear of pupils is the Blowout technique in which the nasal secretion is blown onto a piece of wax paper/plastic film paper [13], [17]. The procedure may be considered as an easy and ready method for use in children with the avoidance of introducing/inserting an instrument of the collection of samples, thereby inconveniencing the children. However, it may not be suitable for younger children who may not be able to blow specimen out from the nostrils. In the present study, the participants were able to produce nasal secretions necessary for performing the nasal smear using the blow-out technique. The limitations to this collection technique are that conditions with limited quantities of nasal secretion do not make any cell yield possible and the area from which the 
cell originates is unknown [17]. Since the present study was not tailored to determine the absolute cell count as the case for quantitative cytology requiring aspiration of samples and dilution with proportional amount of buffered saline [18], the samples produced by the children were adequate for the smear semi-quantitative evaluation.

Cells from the blow-out method are only those which are obtained from the nasal secretion proper and thus reflect a different cell population compared to those collected in the conventional smearing procedure. In the present study, of the cells seen in both the normal and abnormal cytological pictures, only neutrophils were found to be more prominent upon light microscopical examination, whereas very few lymphocytes and nasal mucosal cells of the region were observed in the samples. The categorization of the presence of few neutrophils in the secretions as normal cytological picture in the present study is because it is possible to find few neutrophils and also lymphocytes in the normal nasal mucosa, but presence of moderate and large clumps is observed in pathological conditions [10].

Nasal smear evaluation involves examining the nasal epithelial and infiltrating cells. Mucous, basal, ciliated, and non-ciliated columnar cells make up the epithelium while the migrant cells are Neutrophils, Eosinophil, Lymphocytes, Mast cell and Basophils. The presence of infiltrating cells provides a valuable information about the pathologic condition while the ciliated cells are the first to reveal any pathophysiological process that is occurring in the nasal mucosa. In allergic conditions such as rhinitis, eosinophils and basophils are commonly observed [19], [20], while increased polymorphonuclear cellular infiltration is often indicative of bacterial infection [10]. Increased neutrophilic and lymphocytic infiltration can also be observed in viral infections mostly within 24 hours of infection [10] although other parameters such as ciliated epithelium morphology, are required for proper diagnosis. In the present study, the increased neutrophilic infiltration observed may suggest infection of the children and this was confirmed by the presence of bacteria in the smears.

Increased risk of nasal bacterial infection in children occurs either due to accumulating amounts of secretions, cold, allergies and poor hygiene practices [21]-[23]. As regards hygiene and vulnerability to cold, it is plausible that since the older an individual and higher the level of education one gets, the more likely to heed to instructions on good hygiene and cold preventive measures. This may explain the increased number of abnormal cytological picture observed among the younger pupils in the present study, since they may not yield readily to such practices. Age and grade level of study was found to be significantly associated with the cytological picture and grade of neutrophilic infiltration; however, gender had no such association. Pupils of younger ages (6-8 years) had more neutrophil infiltration in their nasal secretions than the older counterparts (pupils of 9-11 years). Such reflection in the grade levels of 1-3 with respect to those in grade level $4-5$ is not surprising being that grade level of study for children is often associated with age. It is noteworthy that grade level 4 pupils had the least neutrophilic infiltration in their nasal blown secretions, instead of the older pupils in grade 5 as expected. This suggests that other factor(s) apart from age may be playing a role.

\section{CONCLUSION}

The present study performed among pupils in a primary school in Enugu metropolis has shown that there were distinctive differences in the grading scores of neutrophilic infiltrations in the nasal secretion. Increased neutrophilic infiltration was obtained in the nasal secretions of younger schoolchildren below the age of 9 than the older pupils. The blow-out technique used for collection of specimen proves to be a useful and easy technique for children for a semiquantitative assessment of nasal smear. There is, however, a need for further studies to determine the factors that may be associated with an increased risk to respiratory disorders in schoolchildren so as to help alleviate the multi-dimensional impact which nasal infections/inflammatory disorders exerts on their health-related quality of life.

\section{ACKNOWLEDGMENT}

Authors wish to thank the Headmistresses, teachers, and entire staff of WTC primary school for their support, cooperation, commitment, and encouragement throughout the field study period.

\section{REFERENCES}

[1] G. Karlsson, H. A. Hansson, B. Petruson and J. Björkander, "The nasal mucosa in immunodeficiency: surface morphology, mucociliary function and bacteriological findings in adult patients with common variable immunodeficiency or selective IgA deficiency," Actaotolaryngologica, vol. 100, no. 5-6, pp. 456-469, 1985

[2] U. Pipkorn, G. Karlsson, and L. Enerback, "The cellular response of the human allergic mucosa to natural allergen exposure," Journal of allergy and clinical immunology, vol. 82, no. 6, pp. 1046-1054, 1988.

[3] S. M. Walden, D. Proud, R. Bascom, L. M. Lichtenstein, A. KageySobotka, N. F. Adkinson Jr, R. Naclerio, "Experimentally induced nasal allergic responses," Journal of Allergy and Clinical Immunology, vol. 81, no. 5, pp. 940-949, 1988.

[4] H. Malmberg, and E. Holopainen, "Nasal smear as a screening test for immediate-type nasal allergy," Allergy, vol. 34, no. 5, pp. 331-337, 1979.

[5] P. A. Bogaerts and P. A. Clement, "The diagnostic value of a cytogram in rhinopathology," Rhinology, vol. 19, no. 4, pp. 203-208, 1981.

[6] M. Gelardi, L. Lannuzi, N. Quaranta, M. Landi, G. Passalacqua, "Nasal Cytology: Practical Aspects and Clinical Relevance," Clin. Exp. Allergy. vol. 4, pp. 785-792. 2016.

[7] C. Bachert, W. Becker, U. Ganzer, "The role of nasal secretions in allergic diseases of the nose," Arch Otorhinolaryngol, vol. 246, pp. 173-182, 1989

[8] J. J. Holt and E. B. Kern, "A new method of collecting nasal secretions," Otolaryngol Head \& Neck Surg, vol. 94, pp. 403-404, 1986.

[9] M. Mygind and J-A.Wihl, "Concentration of immunoglobulins in nasal secretion from children with recurrent infections in upper airways," Acla Otolaryngol, vol. 82, pp. 216-218, 1976

[10] E. Heffler, M. Landi, C. Causo, S. Fichera, F. Gani, G. Guida, M. T. Liuzzo, M. P. Pistorio, S. Pizzimenti, A. M. Riccio, V. Seccia, M. Ferrando, L. Malvezzi, G. Passalacqua and M. Gelardi, "Nasal Cytology: Methodology with Application to Clinical Practice and Research," Clin Exp Allergy, vol. 48, no. 9, pp. 1092-1106, 2018.

[11] E. Mir, C. Panjabi, A. Shah, "Impact of allergic rhinitis in school going children," Asia Pacific Allergy, vol. 2, no. 2, pp. 93-98, 2012.

[12] I. Jauregui, J. Mullol, I. Davila, M. Ferra, J. Bartra, A. del Cuvillo, J. Montoro, J. Sastre, A. Valero, "Allergic rhinitis and school performance," J Investig Allergol Clin Immunol, vol. 19, no. Suppl 1, pp. 32-39, 2009. 
[13] R. Hastie, J. H. Heroy, D. A. Levy, "Basophilic leucocytes and mast cells in human nasal secretion and scrapping studied in light microscopy. Lab. Invest, vol. 49, pp. 541-554, 1979.

[14] E. O. Meltzer, H. A. Orgel, P. R. Rogenes, E. A. Field, "Nasal cytology in patients with allergic rhinitis: effects of intranasal fluticasone propionate," J Allergy Clin Immunol, vol. 94, pp. 708-715, 1994.

[15] M. Gelardi, M. L. Fiorella, C. Russo, R. Fiorella and G. Ciprandi, "Role of nasal cytology," International Journal of Immunopathology and Pharmacology, vol. 23, no. 1, pp. 45-49, Suppl (2010).

[16] O. Jirapongsananuruk and P. Vichyanond, "Nasal cytology in the diagnosis of allergic rhinitis in children," Ann Allergy Asthma Immunol, vol. 80, no. 2, pp. 165-170, 1998.

[17] U. Pipkorn and G. Karlsson, "Methods for obtaining specimens from nasal mucosa for morphological and biochemical analysis," Eur Respir J, vol. 1, pp. 856-862, 1988.

[18] H. S. Lee, Y. Majima, Y. Sakakura, J. Shinogi, S. Kawaguchi, B. W. Kim, "Quantitative Cytology of Nasal Secretions Under Various Conditions," Laryngoscope, vol. 103, pp. 533-537, May 1993.

[19] B. Miecznik, "Mast Cells in the Cytology of Nasal Mucosa: A Quantitative and Morphologic Assessment and Their Diagnostic Meaning," Ann Allergy, vol. 44, pp. 106-111, 1980.

[20] R. Pawankar, S. Mori, C. Ozu and S. Kimura, "Overview on the pathomechanisms of allergic rhinitis," Asia Pacific Allergy, vol. 1, no. 3, pp. 157, 2011.

[21] M. Gelardi, G. L. Marseglia, A. Licari, M. Landi, I. Dell'Albani, C. Incorvaia, F. Frati, N. Quaranta, "Nasal cytology in children: recent advances," Italian Journal of Pediatrics, vol. 38, pp. 1-5, 2012.

[22] P. J. Cooper, M. Vaca, A. Rodriguez, M. E. Chico, D. N. Santos, L. C. Rodrigues, M. L. Barreto, "Hygiene, atopy and wheeze-eczemarhinitis symptoms in schoolchildren from urban and rural Ecuador," Thorax, vol. 69, no. 3, pp. 232-239, Mar 2014.

[23] A. E. Aiello and E. L. Larson, "What is the evidence for a casual link between hygiene and infections," The Lancet Infectious Diseases, vol. 2, no. 2, pp. 103-110, Feb 2002. 